analysis of individual patient data. Lancet Neurol 2010;9:254-63.

5. Peltola H, Roine I, Fernández J, et al. Hearing impairment in childhood bacterial meningitis is little relieved by dexamethasone or glycerol. Pediatrics 2010;125:e1-8.

6. Hoffman SL, Punjabi NH, Kumala S, et al. Reduction in mortality in chloramphenicol-treated severe typhoid fever by high-dose dexamethasone. $N$ Engl J Med 1984;310:82-8.

7. Paydas S, Akoglu TF, Akkiz H, et al. Mortalitylowering effect of systemic corticosteroid therapy in severe tetanus. Clin Ther 1988;10:276-80.

DOI: 10.1503/cmaj.111-2004

\section{Improving hospital food}

I congratulate Kidd for bringing forward a valuable discussion on improving hospital food. ${ }^{1}$ The entire health care system would benefit if hospitals and other health care institutions provided food that was better able to meet the nutritional needs of those consuming it, staff and patients alike.

However, I am concerned that Kidd uncritically quotes Matt Prentice, the chef responsible for starting a movement to improve hospital food, as follows: "Almost all the fruits and vegetables we use are organic, so yes, that was an increased cost." Since organic produce is more expensive than regular produce, and there is no evidence that it is any more nutritional, I hope that health care institution food services do not decide to waste precious funds purchasing organic produce. There are many evidence-based, cost-effective ways to improve the nutritional value of food, but buying organic produce is not one of them.

\section{Anne Carter MD MHSc}

Community Medicine Residency Program, Queen's University, Kingston, Ont.

\section{Reference}

1. Kidd M. Simple stuff. CMAJ 2010;182;1696. DOI: $10.1503 / \mathrm{cmaj} .110-2129$

\section{Transparency makes for good quality health care}

Having free and secure access to one's medical records is an important step in improving the quality of both primary and specialty medical care. I am a specialist in developmental pediatrics, and for several years, it has been my practice to send a copy of my report to the patient's legal guardian. As indicated in Vogel's article, ${ }^{1}$ giving a patient or parent the opportunity to read what has been written improves communication, encourages patient and family participation, and serves as a method of quality control. On several occasions, proofreading by a parent has resulted in my amending a report, thereby reinforcing the importance of providing accurate information. Medico-legal vulnerablity may also be decreased when the medical report has been reviewed and accepted by the patient or family.

Transparency makes for good quality health care.

\section{Jonathan C. Down MD}

Queen Alexandra Centre for Children's Health, Victoria, BC

\section{Reference}

1. Vogel L. OpenNotes Project "levels the playing field" between doctors and patients. CMAJ 2010; 182:1497-8.

DOI: $10.1503 /$ cmaj.111-2005

\section{Planning for final exit}

CMAJ recently covered a seminar in Toronto at which Dr. Philip Nitschke discussed the right of people of sound mind to decide to end their lives and their right to a safe means to do so. ${ }^{1}$ Readers may have the erroneous impression that the event was sponsored by the First Unitarian Congregation of Toronto.

In fact, the seminar was sponsored by Safe Exit International. Having been denied rentals at other public places in Toronto, the group approached us. We agree that people should be able to choose the time of their own death, and the Canadian Unitarian Council advocates for changes to the law about choice in dying. Safe Exit International, while supporting this concept, also advocates for obtaining illegal drugs or other means of committing suicide. Our position gives equal weight to the need for better palliative care and community support so that terminally ill people receive what they need while they make their choices about death and dying.

Our position is consistent with Unitarian Universalists' core beliefs in the right of conscience and the use of the democratic process within our congregations and society, and that each person has the right to a free and responsible search for truth and meaning.

\section{Ellen Campbell}

President, Board of Trustees

Shawn Newton MDiv

First Unitarian Congregation of Toronto, Toronto, Ont.

\section{Reference}

1. Glauser W. Australian physician advises advance planning for final exit. CMAJ 2010;182:E815-6.

DOI: $10.1503 / \mathrm{cmaj} .111-2000$

\section{Codeine v. morphine}

Thank you for identifying the risks associated with codeine's wide use in Canada as a perceived safe and effective analgesic. ${ }^{1}$ As a family physician, I respectfully suggest that the use of morphine instead of codeine for pain relief in children might lead to another serious side effect: unrelieved pediatric pain. Given the lack of education on chronic pain in most Canadian undergraduate medical curricula as well as recent concerns about overuse of opiates leading to addiction and diversion, ${ }^{2,3}$ I suspect that many nonspecialist physicians will be loathe to use morphine when needed. Parents may also raise concerns about using what they perceive to be a very potent opiate for their children.

Tramadol, which has been shown to be safe and effective in children, ${ }^{4}$ may be more acceptable for moderate noncancer pain, provided that drug plans cover it. Our pediatrician colleagues can support those of us in primary care by commenting on the safety and efficacy of this drug, which has been widely used for decades in other countries. In the meantime, if we rashly discard codeine, let's be sure we have a 